\title{
Advances in Structures for Large Space Systems
}

\author{
W. Keith Belvin ${ }^{*}$ \\ NASA Langley Research Center, Hampton, VA 23681
}

\begin{abstract}
The development of structural systems for scientific remote sensing and space exploration has been underway for four decades. The seminal work from 1960 to 1980 provided the basis for many of the design principles of modern space systems. From 1980 2000 advances in active materials and structures and the maturing of composites technology led to high precision active systems such those used in the Space Interferometry Mission. Recently, thin-film membrane or "gossamer" structures are being investigated for use in large area space systems because of their low mass and high packaging efficiency. Various classes of Large Space Systems (LSS) are defined in order to describe the goals and system challenges in structures and materials technologies. With an appreciation of both past and current technology developments, future technology challenges are used to develop a list of technology investments that can have significant impacts on LSS development.
\end{abstract}

\section{Introduction}

Since the launch of ECHO, many ideas for large systems in space have been vigorously pursued, however, relatively few have become operational. This paper summarizes past successes and future challenges in the design and implementation of Large Space Systems (LSS) including concepts, analysis and testing.

NASA's future exploration missions will likely entail the in-space assembly of various large space systems for sensing, habitation, power, and propulsion. A description of these requirements is included to provide direction for future large space systems development. The goal is to improve the rigor of LSS research and development, thereby increasing the number of systems in space operation.

In particular, the potential benefits of modular assembly and automation technology is described. The paper also addresses current research to advance large, high precision structures with an eye to past experience and insights. For example, the use of composite structures that can be inflation deployed and "rigidized" in space are discussed.

The definition of LSS classes are defined first, followed by a brief review of past LSS developments. Recent LSS technology development efforts are then discussed for each class of LSS. Subsequently, LSS needed for future exploration missions are discussed and then used to develop a list of promising technologies for the advancement of LSS.

\section{Classes of Large Space Systems}

Structural requirements for large space systems depend strongly on both environmental and operational loads and on the mission demands for agility, geometric precision and size. For example, solar sails need not be highly agile for navigation and control, hence, the primary loading is due to environmental (solar pressure) loading. The propulsive force objective for solar sails leads to low mass designs since the propulsive acceleration of the sail system is due only to momentum transfer from photons. Thus, solar sails are classed in this paper as lightly loaded, low mass or gossamer large space systems. Figure 1. shows the four classes of LSS used in this paper.

Gossamer Structures (GS) are characterized by being lightly loaded, low mass systems such as membrane dominated structures used for solar reflection or collection, e.g. solar sails, arrays, shields, and concentrators. These systems are mass driven designs with minimal requirements for shape and pointing. Stiffness and strength are active constraints, but mass is the dominant consideration in both concept development and materials selection.

Large Aperture Sensorcraft (LAS) consist of telescopes and antennas used to collect and/or radiate photons for remote sensing. Antennas and telescopes rely upon electromagnetic radiation from RF to Optical wavelengths, respectively, for sensing of properties of interest. To operate properly, the surface precision of antennas and

${ }^{*}$ Chief Engineer for Space, Structures and Materials Competency, 4 West Taylor Street/MS 230, Associate Fellow AIAA. 

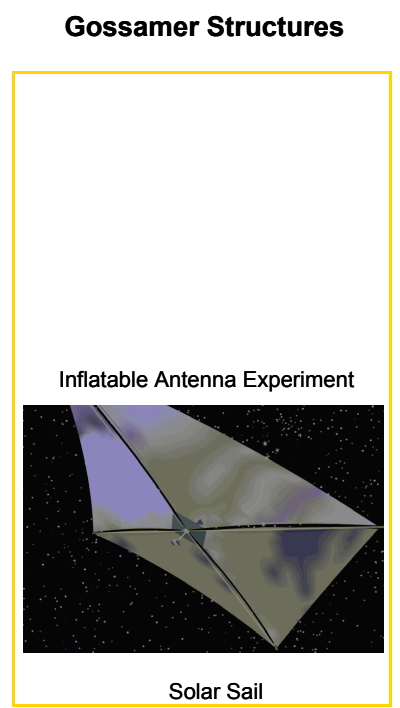

Large Aperture Sensorcraft

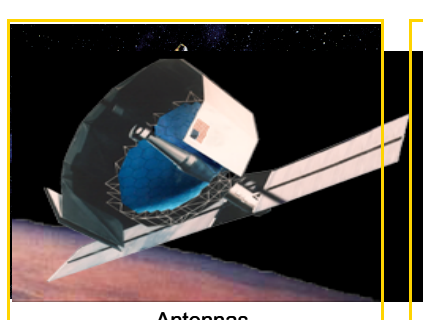

Antennas

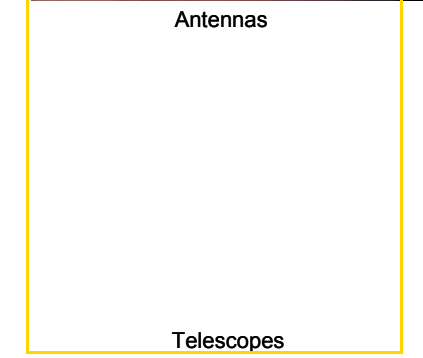

In-Space Platforms And Surface Systems

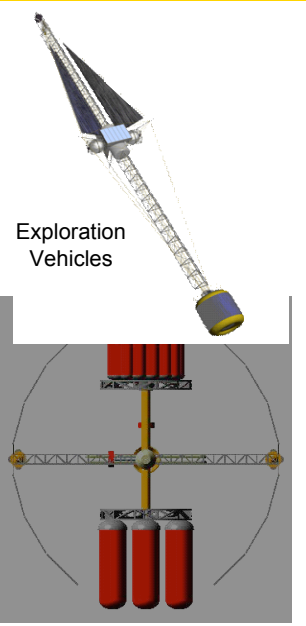

Planetary Access Vehicles

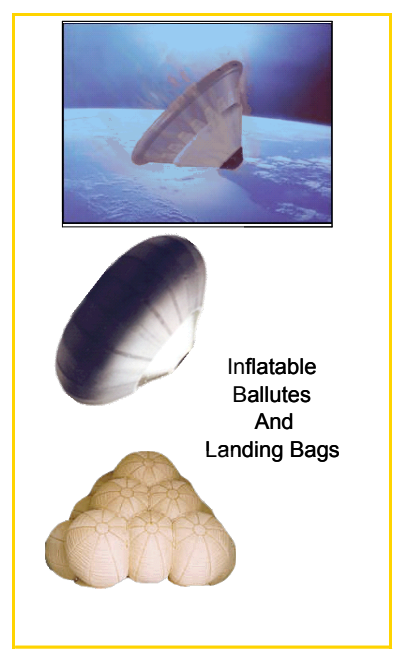

Figure 1. Four Classes of Large Space Systems

telescopes usually requires a root-mean-square (RMS) accuracy of a fraction of a wave length of the electromagnetic spectrum being measured. As stated by Hedgepeth (Ref. 1-2) precision dominated spacecraft are stiffness driven designs. Mass and strength are active constraints, but achieving and maintaining the desired shape requires stiffness and stability to be the drivers for the architecture and materials selection. It should be noted that much work is underway to extend gossamer structures (GS) to meet the precision requirements of LAS.

In-Space Platforms and Surface Systems (ISP\&SS) represent the diverse set of architectures and devices needed to achieve long-term presence in space for exploration. Examples of ISP\&SS include solar power stations, cryogenic fuel depots, artificial gravity vehicles, human habitats, and staging platforms for modular assembly and construction of reconfigurable vehicles. While this class of LSS is broad, the common themes for design are the need for strength and long-life. For example, surface structures and habitats may be pre-positioned on Mars 10 years in advance of the arrival of an exploration crew. While mass is an active constraint, space durability and strength based considerations dominate the design of ISP\&SS.

Planetary Access Vehicles (PAV) are included in this LSS class definition to recognize the role deployable appendages can contribute to PAV sizing and thermal requirements. These vehicles are usually small in scale compared to large apertures, yet they can utilize deployable appendages such as inflatable aeroshells and parachutes to reduce vehicle temperatures and speed when an atmosphere is present, and gas filled membranes to cushion PAV landing. PAV appendages currently consist of membrane deployed structures, although they are not considered GS due to the high operational loads.

\section{Past Experience with LSS}

Artificial satellites were first introduced during the cold war between the United States and the Soviet Union. Sputnik was the first artificial satellite to be launched in 1958. In 1960, the United States launched the first large space structure, ECHO. This satellite deployed as a sphere to a diameter of $30.5 \mathrm{~m}$, much larger than the launch vehicle shroud. Echo definitely fell within the GS class of LSS as the constraints on launch mass and payload volume required ingenuous use of an inflated 12.5 um mylar membrane (Ref. 3). Echo was used to demonstrate the reflection of radio frequency wavelengths of EM radiation. A somewhat unintended demonstration of solar sail pressure was also observed as the altitude of the satellite increased during the sun illuminated portion of the orbit.

During the 1960's a number of communication satellites were flown, including the Radio Astronomy Explorer (RAE) (Ref. 4) which utilized two stem type booms deployed to a total length of $457 \mathrm{~m}$. This structure bridges the categories of GS and LAS. The RAE was used to measure celestial radio sources, but it did not require the precision of today's reflector based systems. The RAE was gossamer in the use of very long lightweight booms under gravity gradient loading.

In the 1970's, the need for large apertures was widely recognized for both sensing and propulsion. Conceptual designs of solar sails for comet rendezvous were explored as documented in Ref. 5. Technology challenges to achieve the low areal density included ultra-thin space durable films and gossamer booms to maintain the sail 
membrane shape. The technology challenges for guidance, navigation, and control of such a large sail system was well beyond the state-of-the-art. Packaging and deployment/assembly of large platforms for remote sensing also became a fundamental challenge due to limited launch vehicle mass and volume.

The identification of structures and materials limitations for LSS provided the impetus for NASA and DoD to develop a large space systems technology (LSST) program. This program paved the way for the seminal design guides such as that by Hedgepeth, Freeland, Mikulas, et. al. (Ref. 6-9). These works identified the key design parameters including environmental and operational loads, stiffness based design for precision, and control structure interaction. Concepts for sails, telescopes, antennas, power systems and other LSS were developed and analyzed during the 1970-1980's.

Of particular note is the commercial need (technology pull) for high gain reflector antennas used for communication. The development of large mesh antennas was successfully accomplished during this period which led to a large number of communication satellites. Technology from the $15 \mathrm{~m}$ hoop-column antenna, shown in Fig. 2 (Ref. 10), and the wrap-rib antenna (Ref. 11) was successfully transferred into a number of commercial mesh antenna systems, some still operating today.

In the next section, technology development efforts in all four classes of LSS are discussed with an aim at understanding the challenges and system impacts of these investments.

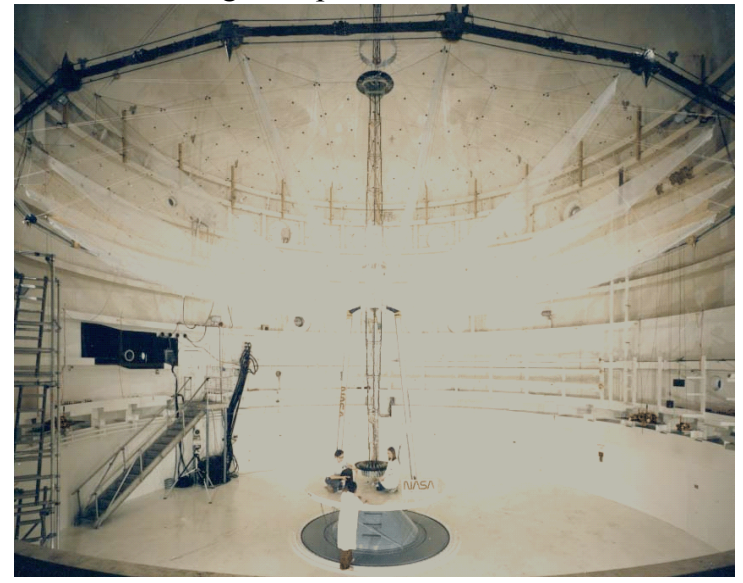

Figure 2. 15 Meter Hoop Column Mesh Antenna

\section{Recent Efforts and Challenges for LSS}

Gossamer Structures - The United States launched ECHO in 1960 which was the first GS. Since then, membrane structures have been used for various mission objectives such as tracking, RF communications, entrydescent-landing (EDL), solar power, and for thermal control. Three examples of current research and development for GS follow; solar sails, lenticular reflectors, and solar arrays.

Structures and materials technology for solar sails has advanced rapidly over the last five years with focused investments from NASA. Currently two sail providers are constructing $20 \mathrm{~m}$ square sails for ground testing of deployment and for structural characterization. The L'Garde concept utilizes aluminized mylar membranes and inflation deployed rigidizable (IDR) booms to transmit the solar pressure loads to the center body (Ref. 12). Similarly, the AEC-Able / SRS configuration shown in development in Fig. 3 utilizes aluminized CP1 membranes and strain energy deployed coilable longeron booms to react the solar pressure loads (Ref. 13). Both of these systems are maturing rapidly in preparation for space flight experiments. The extreme challenge for solar sails is to minimize mass such that the characteristic acceleration can be maximized. Thus, design and fabrication methods that enable the lowest mass system to meet the objective of sunlight reflection are critital. The second technology area of high importance to solar sails is the analysis models used for prediction of shape, loads, and dynamics. In turn, these models feed the GNC design and simulation of solar sails. Ref. 14 gives a good description of some of the challenges in using finite element codes for structural analysis of solar sails. In addition, the analysis of wrinkling in solar sail membranes is discussed in Refs. 1520

Lenticular reflectors such as the Inflatable Antenna Experiment (IAE) shown in Fig. 1 allow photons to be collected and focused for a variety of objectives such as solar concentration or radio frequency communications. These GS systems utilize an inflated lens and torus to provide a parabolic shape for photon collection and

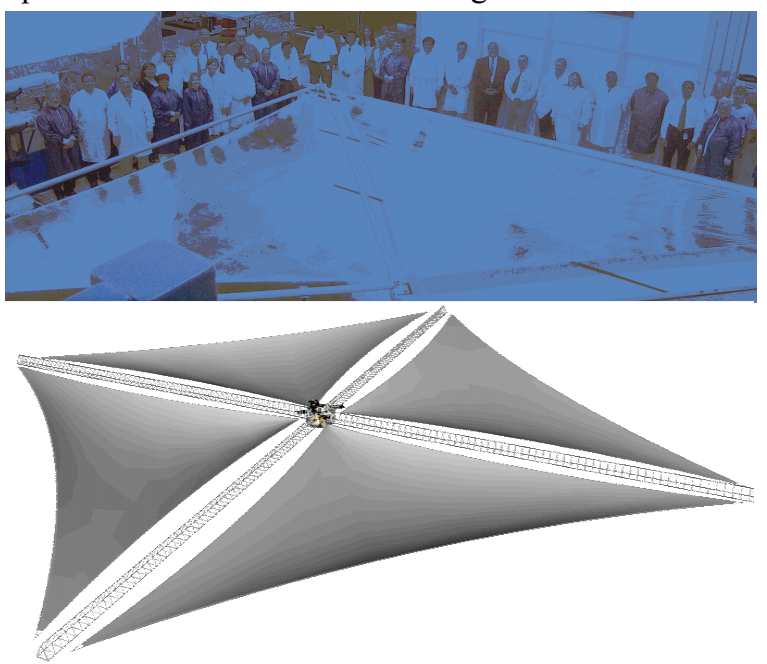

Figure 3. AEC-ABLE/SRS Solar Sail Development 
focusing. The IAE described in Ref. 21 is an excellent example of a flight experiment to demonstrate the potential of lenticular GS. The key challenges with lenticular systems involves micro-meteriod and orbital debris (MMOD) considerations. To this end, various efforts are underway to develop self-healing materials and rigidizable lense/torus systems that do not require inflation pressure to be maintained. Work is now underway to develop hybrid systems whereby fixed reflectors are augmented with deployable reflectors to increase aperture size as described in Ref. 22.

For many years panel type solar arrays have been used to convert solar radiation energy to electrical power. More recently, thin film solar cells have been developed that can be used with flexible circuitry to permit flexible membrane solar arrays with the potential to exceed $100 \mathrm{Watts} / \mathrm{m}^{2}$. Various GS solar array architectures are made possible with flexible membrane arrays. GS membranes have also been used to increase the effective area of an array be reflecting the sun's radiation onto the solar cells. Flexible membranes have also been employed to form local concentrators distributed along the solar array to decrease the area populated by solar cells. This method, see Ref. 23, can use either flat fresnel lenses or curved membrane lenses. These distributed concentrators are a very cost effective way to lower system cost and increase the power to mass efficiency.

Large Aperture Sensorcraft - A sensorcraft is defined herein as a satellite which does not use the concept of a bus to support an instrument. In other words, the satellite structure and its payload are so integral that they cannot be developed independently. The two prime examples of this type of spacecraft are large antennas and telescopes. The requirements of large remote sensing apertures for NASA's science enterprises were published in a 2003 technology solicitation (Ref. 24) as shown in Tables 1 and 2 for RF and optical systems, respectively. The need for higher spatial and temporal resolutions continues to drive the need for large, high precision apertures.

Antennas for communications and radiometry have been widely utilized as mentioned previously. Mesh antenna technology such as the ASTRO-MESH, (Ref. 25) has already achieved $12 \mathrm{~m}$ by $16 \mathrm{~m}$ in size. The primary challenge for RF LAS is to increase the frequency of operation which may necessitate the transition from a mesh to a membrane surface. Also, the need for increased aperture size continues in order to improve spatial resolution. State of the art for mesh antennas is the use of mechanical deployable systems involving hinges and latches. Investigations are underway to replace some or all of these systems with "solid state" materials that perform the necessary geometric changes during deployment. Elastic memory composites (Ref. 26) and strain energy deployed hinges (Ref. 27) are a few of the promising technologies for LSS deployment.

Table 1 Goals for NASA Radiometers and Radars

\begin{tabular}{|c|c|c|c|c|c|}
\hline & \multicolumn{2}{|c|}{ Radiometers } & \multicolumn{3}{|c|}{ RADARs } \\
\hline & $\begin{array}{c}\text { Filled } \\
\text { Aperture } \\
\text { Antenna }\end{array}$ & $\begin{array}{l}\text { Distributed/Synthetic } \\
\text { Aperture Radiometer }\end{array}$ & $\begin{array}{c}\text { Filled } \\
\text { Aperture }\end{array}$ & $\begin{array}{c}\text { Synthetic } \\
\text { Aperture } \\
\text { Radar } \\
\text { (SAR) }\end{array}$ & $\begin{array}{c}\text { Inter- } \\
\text { ferometric } \\
\text { SAR }\end{array}$ \\
\hline $\begin{array}{l}\text { Operational } \\
\text { Frequencies }\end{array}$ & $\begin{array}{c}1.4-300 \\
\mathrm{GHz}\end{array}$ & $\begin{array}{l}1.4 \mathrm{GHz}- \\
183 \mathrm{GHz}\end{array}$ & $\begin{array}{c}1.2-94 \\
\mathrm{GHz}\end{array}$ & $\begin{array}{r}100 \mathrm{MHz} \\
-18 \mathrm{GHz} \\
\end{array}$ & $1.2-18 \mathrm{Ghz}$ \\
\hline Array Size & $\begin{array}{l}25-50 \mathrm{~m} \\
\text { diameter }\end{array}$ & $25-50 \mathrm{~m} \times 25-50 \mathrm{~m}$ & $\begin{array}{c}\text { Curved } \\
\text { Apertures } \\
6-25 \mathrm{~m} \\
\\
\text { Planar } \\
>100 \mathrm{~m}^{2} \\
\end{array}$ & $\begin{array}{c}\text { Linear } \\
50-100 \mathrm{~m} \\
\mathrm{x} \\
3-5 \mathrm{~m}\end{array}$ & $\begin{array}{l}50-100 \mathrm{~m} \mathrm{x} \\
3-5 \mathrm{~m}\end{array}$ \\
\hline $\begin{array}{c}\text { Array/Aperture } \\
\text { Areal Density }\end{array}$ & $\begin{array}{l}\text { Mesh or } \\
\text { membrane } \\
<2 \mathrm{~kg} / \mathrm{m}^{2}\end{array}$ & $<2 \mathrm{~kg} / \mathrm{m}^{2}$ & $<3 \mathrm{~kg} / \mathrm{m}^{2}$ & $<3 \mathrm{~kg} / \mathrm{m}^{2}$ & $<3 \mathrm{~kg} / \mathrm{m}^{2}$ \\
\hline
\end{tabular}


Table 2 Goals for future NASA Optical Systems

\begin{tabular}{|c|c|c|c|c|c|c|}
\hline 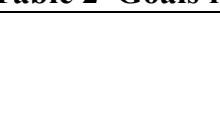 & $\begin{array}{c}\text { X-ray } \\
\text { mirrors }\end{array}$ & $\begin{array}{c}\text { UV } \\
\text { Mirrors }\end{array}$ & Visible & $\begin{array}{l}\text { Scanning } \\
\text { Lidar } \\
\text { Telescope }\end{array}$ & $\begin{array}{c}\text { NIR Earth } \\
\text { Science } \\
\text { Systems }\end{array}$ & $\begin{array}{c}\text { Far } \\
\text { infrared } \\
\text { to submm }\end{array}$ \\
\hline $\begin{array}{l}\text { Wavelength / } \\
\text { Energy Range }\end{array}$ & $\begin{array}{ll}0.05 & -15 \\
\mathrm{keV} & \end{array}$ & $\begin{array}{l}100-400 \\
\mathrm{~nm}\end{array}$ & $400-700 \mathrm{~nm}$ & $355-2050 \mathrm{~nm}$ & $\begin{array}{l}0.7-4 \\
\square \mathrm{m}\end{array}$ & $\begin{array}{l}20-800 \\
\square \mathrm{m}\end{array}$ \\
\hline Size & $1-4 m$ & $1-2 m$ & $6-10+m$ & $0.7-1.5 \mathrm{~m}$ & $3 m-4 m$ & $10-25 \mathrm{~m}$ \\
\hline $\begin{array}{c}\text { Areal } \\
\text { Density }\end{array}$ & $\begin{array}{l}<0.5 \\
\mathrm{~kg} / \mathrm{m}^{2} / \\
\text { grazing } \\
\text { incident }\end{array}$ & $\begin{array}{ll}< & 10 \\
\mathrm{~kg} / \mathrm{m}^{2} & \end{array}$ & $<5 \mathrm{~kg} / \mathrm{m}^{2}$ & $<10 \mathrm{~kg} / \mathrm{m}^{2}$ & $<5 \mathrm{~kg} / \mathrm{m}^{2}$ & $<5 \mathrm{~kg} / \mathrm{m}^{2}$ \\
\hline
\end{tabular}

Radar systems continue to be desired by the Department of Defense and by NASA for planetary reconnaissance. Phase array radars have provided a new dimension to LAS design be providing the ability to electronically adjust the phase of these radar systems in order to compensate for shape and pointing errors in the structural strong back. Now the design of the structure and the radar must be performed in parallel with design error budgets reflecting this new form of dimensional error compensation. DARPA has an Innovative Space-based Antenna Technology (ISAT) program to develop large antennas. One key aspect of this program is the development of inflation deployed rigidizable (IDR) structures. IDR structures offer the potential of few moving parts with relatively high packaging efficiency. Thus the potential for lower cost and risk for LSS is possible should robust IDR technologies be developed. Various investigations to mature IDR structures and materials are underway (Refs. 28-31)

The largest telescope in space is the Hubble Space Telescope (HST) (Ref. 32). The HST is to be replaced with the James Webb Space Telescope (JWST) shown in Fig. 4 and described in Ref. 33. The aperture will increase from the HST monolithic mirror diameter of $2.3 \mathrm{~m}$ to a segmented $\sim 6 \mathrm{~m}$ mirror for JWST. This is a large improvement; however, telescope apertures of $\sim 15 \mathrm{~m}$ are desired for future space science missions (Ref. 34). Unlike apertures operating at the radio frequency portion of the EM spectrum, telescopes operate at the visible and infrared portions of the spectrum. This short wavelength necessitates that the precision of the reflecting surface be much higher than for antennas. This high precision requires careful preparation of the mirror surface and highly stable structural support. Beyond selection of highly stable materials, such as low coefficient of thermal expansion (CTE) composites, two active approaches are employed to achieve the desired optical performance. First, wavefront correction is often employed by the use of deformable mirrors at secondary or tertiary mirrors to compensate for primary mirror distortions. The second approach is to use metrology and actuation to mechanically adjust the geometry of key portions of the telescope. This latter technique is to be employed by the Space Interferometry Mission (SIM) (Ref. 35).

Two additional technological approaches for telescope design are under ground test evaluation. First, the Dual Anamorphic Reflecting Telescope

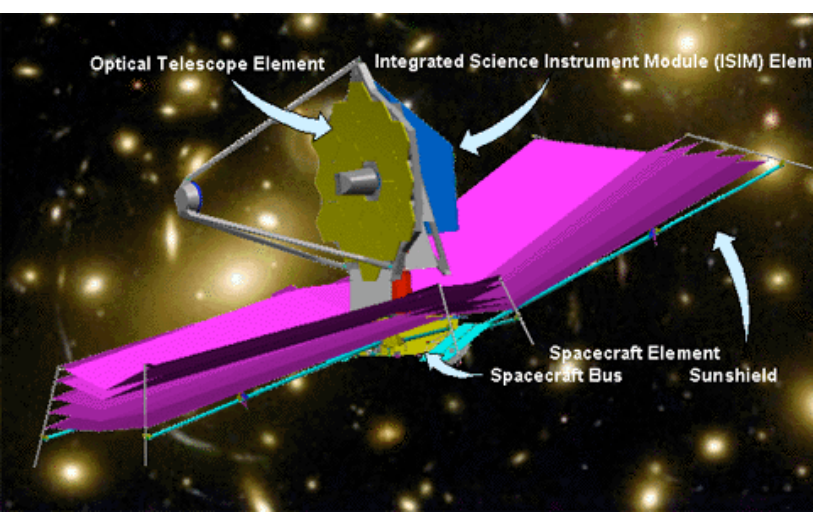

Figure 4. James Webb Space Telescope (DART) (a schematic ray trace is shown in Fig. 5), is a novel approach to avoid the need for double curvature of the primary mirror (Ref. 36). In the DART architecture, two singly curved mirrors are positioned to perform the focusing of light onto a secondary mirror. Since only single curved mirrors are needed, the possibility of deforming continuous thin "membrane" mirrors can be achieved without producing wrinkles. Another approach is to use thin polyimide films with nanometer surface precision to create either flat facet mirrors or other geometries using ingenuous shaping mechanisms (Ref. 37). 
Finally, a key design challenge for LAS is development of integrated design and simulation tools that simulate the end-toend performance of the system. The assignment of error budgets to various subsystems such as structures can result in either under- or over-design at the system level. Integrated simulation tools are required such that the full design space is used to develop cost effective solutions.

In-Space Platforms and Surface Systems- The best example of a LSS that falls in the ISP\&SS class is the International Space Station (ISS). The ISS consists of a structural strong back with many modules and appendages for logistics, habitation, power and propulsion. The success of the ISS is due to careful planning and simulation during construction. Unfortunately, the schedule and cost of achieving the fully operational ISS is not a model to be emulated for future exploration missions.

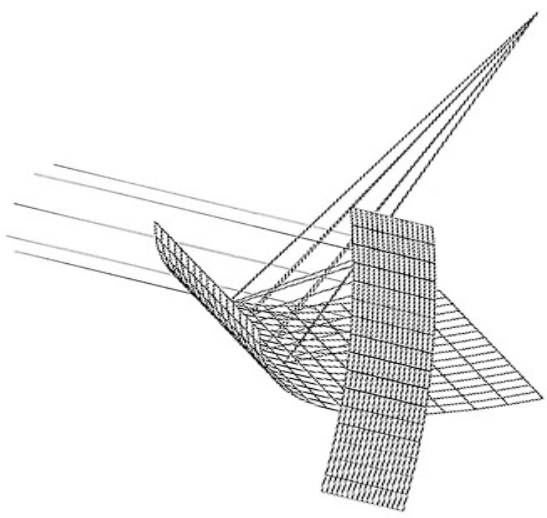

Figure 5. Dual Anamorphic Reflector Telescope Ray Trace Schematic

While no surface systems yet exist in the LSS class, technology solicitations are underway to begin the process of defining creative solutions to the cost constraints always present in space missions (Ref. 38). New architectures and technologies that provide for spiral development at a cost that can be incrementally planned are needed to provide real system level cost and risk reduction. Since these efforts are just beginning, ISP\&SS technologies for exploration missions are discussed in the next section (Future Missions).

Planetary Access Vehicle - A previously mentioned, the PAV focus in this paper is not on the vehicle proper, but on the appendages used to help guide a PAV through entry-descent-landing (EDL). The high energy associated with a PAV often requires some method of dissipating the energy using aeroshells, ballutes and/or parachutes. NASA's In-Space Propulsion program is investing in technologies to improve the performance of EDL systems. Inflation deployed aeroshells or ballutes are under study. The possibility of using inflation deployed rigidizable (IDR) structures may offer benefits for EDL as well.

Inflation deployed landing bags have been demonstrated successfully with three landings on Mars. These highly successful landings will likely continue to push landing bag technologies for use with more massive payloads. In addition, the concept of multifunctional EDL appendages such as a ballute that also serves as a landing bag are intriguing. Much work in concepts and structures and materials technology is needed to reach the full potential of LSS to assist EDL. For example, higher temperature aeroshell materials systems could help increase the payload mass fraction of PAVs.

\section{Future Missions}

NASA's science and exploration missions of the future will utilize all four classes of LSS. Tables 1 and 2 have listed some of the requirements for LAS needed by the Earth and Space Science communities. New emphases on technical approaches that reduce cost (and schedule) are beginning to be solicited either directly or implicitly as part of proposal review criteria. The potential for GS to enable lightweight antennas and telescopes offers the hope of reducing costs, however, risk mitigation for GS technology is needed since analysis and ground testing for GS systems is difficult at best.

Human and robotic exploration of space entails the development of transfer vehicles, cryogenic fuel depots, power and infrastructure platforms, habitats (both in-space and surface), and many other yet to be defined as illustrated in Fig. 6. An aspect of the exploration that cannot be over emphasized is spiral development whereby missions build upon previous successes in order to achieve more challenging missions. This philosophy of development permeates LSS technology development approaches. For example, LSS technologies must also entail a spiral approach to development such that periodic system level benefits are produced based on previous investments. 
An example of transformational technologies that enable LSS spiral development are modular/reconfigurable systems. Modular systems not only provide for a convenient means of in-space deployment/construction, they also permit a building block approach to develop ever more capable systems. For example, consider a telescope whose aperture size could be periodically increased. In addition to being modular in assembly, these systems also possess the ability to be reconfigured should new missions require different functionality. The ability to pre-stage propellants, habitats, and power systems and configure them for mission specific objectives transforms the current concept of an LSS designed for only one mission.

The next section describes the system level impact of current structures and materials subsystem technologies.

\section{Large Space Systems Technology Investment}

Technology developments can produce four primary impacts to the system under development: enabling for the mission; performance enhancing; cost reduction; and risk amelioration. Some technologies can be transformational in that they supplant previous approaches. While much emphasis has been placed on enabling technologies and increased technical performance, a subtle shift is taking place to raise the importance of technologies that reduce cost and risk.

Table 3 lists selected technologies and their relevant impact on LSS for each of the four classes. This list should not be considered
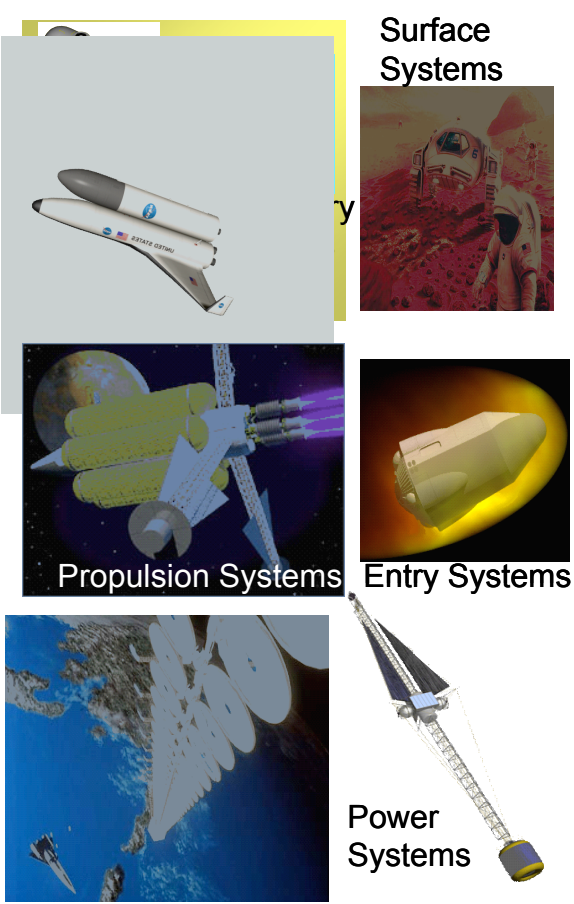

Figure 6.LSS for Future Exploration Missions complete or unchanging with time. The purpose of this list is to aid technologists and investors to consider the system impact of their efforts. Rigorous subsystem technology requirements need to be developed using a system perspective. Once this occurs, managing the technology research and development to meet the derived requirements for that subsystem will insure that success will translate into meaningful system level impacts. Hence, the goal of such a technology/system impact list as Table 3 should be to encourage more rapid development and implementation of LSS in space.

Table 3 System Level Impacts of Selected Technology Trusts *

\begin{tabular}{|c|c|c|c|c|c|}
\hline & & & Clas & f LSS & \\
\hline & Technology & GS & LAS & ISP\&SS & PAV \\
\hline Concepts/Architecture & & & & & \\
\hline & Modular/Reconfigurable & & $\mathrm{PE}$ & TR & \\
\hline & DART & & TR & & \\
\hline $\begin{array}{l}\text { Deployment/Assembly } \\
\text { /Construction }\end{array}$ & & & & & \\
\hline & Inflation & PE, RR & $\mathrm{CR}$ & $\mathrm{PE}$ & EN \\
\hline & Mechanical/Strain Energy & RR & PE, RR & CR, RR & \\
\hline & Robotic/Human & & PE, RR & TR & \\
\hline Structures & & & & & \\
\hline & IDR & PE, RR & PE, CR & $\mathrm{CR}$ & $\mathrm{PE}$ \\
\hline & Radiation Protection & & $\mathrm{PE}$ & EN & \\
\hline & Multifunctional & & & EN & \\
\hline & Active & PE, RR & EN, RR & $\mathrm{PE}$ & \\
\hline Materials & & & & & \\
\hline & Rigidizable & $\mathrm{PE}$ & PE,CR & PE, CR & $\mathrm{PE}$ \\
\hline & Self Healing & PE, RR & RR & PE, RR & \\
\hline & Active / Morphing & $\mathrm{PE}$ & En, RR & $\mathrm{PE}$ & \\
\hline & Extreme Temperature & $\mathrm{PE}$ & EN & EN & EN \\
\hline & Radiation Amelioration & & & EN, RR & \\
\hline
\end{tabular}




\begin{tabular}{|l|l|c|c|c|c|}
\hline Analysis & \multicolumn{5}{|l|}{} \\
\hline & FEM / Distributed Parameter & PE & PE & PE & PE \\
\hline & Constitutive Model Properties & EN & EN & EN & EN \\
\hline & Integrated Simulation & RR & EN, CR & EN, RR & EN, RR \\
\hline $\begin{array}{l}\text { Metrology/ } \\
\text { Health Monitoring }\end{array}$ & \multicolumn{5}{|l|}{} \\
\hline & Non- Contacting Metrology & PE & EN & PE & \\
\hline & Integral Sensing & & PE & EN & \\
\hline Testing & \multicolumn{5}{|l|}{} \\
\hline & Facilities and Equipment & EN & EN & PE, PR & PE, RR \\
\hline & Methods & EN & PE, CR & PE, CR & PE, CR \\
\hline
\end{tabular}

* EN - Enabling, PE - Performance Enhancing, CR- Cost Reduction, RR - Risk Reduction, TR - Transformational

\section{Conclusion}

Space based remote sensing continues to demand large apertures for higher temporal and spatial resolution. Space exploration mission requirements are still in development, nevertheless, transformational technologies such as modular, reconfigurable platforms and vehicles will be crucial to developing cost effective architectures. Technology development for Large Space Systems has and will continue to provide significant improvements over state-of-the-art if a systems perspective is employed to evaluate the impact of subsystem technologies. The concept of subsystem technology impacts on system level requirements was introduced to delineate large space systems technology classes and to guide investment decisions. The goal of this approach to technology assessment is to provide a more rigorous approach to LSS technology development in order to meet the needs of future missions that require large space systems.

\section{References}

1. Hedgepeth, John, M., Mikulas, Martin M., Jr. and MacNeal, Richard H., "Practical Design of Low-Cost Large Space Structures," Aeronautics and Astronautics, October 1978, pp. 30-34.

2. Hedgepeth, John. M., "Critical Requirements for the Design of Large Space Structures," NASA CR 3484, 1981.

3. Jaffe, L., "Project Echo Results," Astronautics, Vol. 6, No. 5 (May 1961).

4. Herzel, George G., Principal Contributor, "Tubular Spacecraft Booms (Extendible, Reel Stored)," NASA SP 8065, Feb. 1971.

5.. Wright, Jerome L., "Space Sailing" Gordon and Breach Science Publishers, Philadelphia, 1992.

6. Hedgepeth, John M., "Design Concepts for Large Antenna Reflectors," Large Space Systems Technology, NASA CP-2168, 1980, pp. 103-119

7. Bush, Harold, Mikulas, Martin M., and Heard, Walter L., "Some Design Considerations for Large Space Strcutures," Presented at the AIAA/ASME $18^{\text {th }}$ Structures, Structural Dynamics, and Materials Conference, San Diego, CA, 21-23 March, 1977, Paper no. 77-395.

8 Hedgepeth, John M., MacNeal, Richard H., Knapp, Karl, and MacGillivray, Charles S., "Considerations in the Design of Large Space Structures.” NASA CR-165744, 1981.

9 Hegepeth, John M., "Support Structures for Large Infrared Telescopes," NASA CR-3800, 1984.

10 Campbell, T. G., Butler, D. H., Belvin, W. K., and Allen B., "Development of the 15-Meter Hoop-Column Antenna Concept," NASA CP-2368, pp. 167-212, Presented at the Large Space Antenna Systems Technology Conference, Dec. 4-6, 1984, Hampton, VA.

11 Freeland, R. E., Garcia, N. F., and Ewamoto, H., "Wrap-Rib Technology Development, “ NASA CP-2368, pp. 139-166, Presented at the Large Space Antenna Systems Technology Conference, Dec. 4-6, 1984, Hampton, VA.

12 Lichodziejewski, D., Derbes, B., West, J. Reinert, R. Belvin, K. and Pappa, R., "Bringing an Effective Solar Sail Design Toward TRL 6", Proceedings of the Joint Propulsion Conference, Huntsville, AL, May 2003, AIAA 20034659 .

13. Murphy D. M., Trautt T., McEachen M., \& Messner D., Laue G., and Gierow P. A. , "Progress and Plans for System Demonstration of a Scalable Solar Sail" Proceedings of the 14th AAS/AIAA Space Flight Mechanics Conference, Hawaii, February 2004.

14 Taleghani, B. K., Sleight, D. W., Muheim, D., Belvin, K. and Wang, J.., "Assessment of Analysis Approaches for Solar Sail Structural Response", Proceedings of the Joint Propulsion Conference, Huntsville, AL, May 2003, AIAA 2003-4500. 
15 Jenkins, C. H. M., Editor; Gossamer Spacecraft: Membrane and Inflatable Structures Technology for Space Applications, Progress in Astronautics and Aeronautics Hardcover, 586 page(s), ISBN or Order Number: 1-56347403-4, Copyright: 2001

16 Su, Xiaofeng; Abdi, Frank; Taleghani, Barmac K.; and Blandino, Joseph R.; "Wrinkling Analysis of a Kapton Square Membrane Under Tensile Loading," Norfolk, Virginia, AIAA 2003-1985, 44th AIAA/ASME/ASCE/AHS/ASC Structures, Structural Dynamics, and Materials Conference, April 7-10, 2003, Norfolk, VA..

17 Leifer, J., and Belvin, W., "Prediction of Wrinkle Amplitudes in Thin Film Membranes Using Finite Element Modeling" AIAA 2003-1983, Proceedings of the 44th AIAA/ASME/ ASCE/AHS/ASC Structures, Structural Dynamics, and Materials Conference, Norfolk, VA April 2003

18 Johnston, John; "Finite Element Analysis of Wrinkled Membrane Structures for Sunshield Applications," $43^{\text {rd }}$ AIAA/ASME/ASCE/AHS/ASC Structures, Structural Dynamics and Materials Conference, Denver, CO, AIAA 2002-1456, April 22-25, 2002.

19 Jenkins, C.H., Fitzgerald, D., and Liu, X. (2000), "Wrinkling of an inflated membrane with thermo-elastic boundary restraint," 41st AIAA/SDM Space Inflatables Forum, Atlanta, GA.

20 Tessler, Alexander; and Sleight, David W.; "Toward Effective Shell Modeling of Wrinkled Thin-Film

Membranes Exhibiting Stress Concentrations", 45th AIAA/ASME/ASCE/AHS/ASC Structures, Structural Dynamics and Materials Conference, Palm Springs, California, AIAA 2004-1739, April 19-22, 2004.

21 Freeland, R. and Bilyen, G. "Instep Inflatable Antenna Experiment" 43rd Congress of the International Astronautical Federation, August 28 - September. 5 1992, Washington, D.C.

22 Willey, C. E., Schulze, R. C., Bokulic, R. S., Skullney, W. E. Line, J. K., Cadogan, D. P., and Knoww, C. F., "A Hybird Inflatable Dish Antenna System for Spacecraft," 42 ${ }^{\text {nd }}$ AIAA/ASME/ASCE/AHS/ASC Structures, Structural Dynamics, and Materials Conference, April 16-19, 2001, Seattle, WA.

23 O’Neill, Mark J. et. al; "The Stretched Lens Array Ultra-Light Concentrator Array," $28^{\text {th }}$ IEEE-PVSC, 2000.

24 NASA Research Announcement, "Mission and Science Measurement Technology - 2004," NRA 03-OAT-01, August 4, 2003.

25 Thompson, Mark, "Keep it Simple: Considerations for the Design of Large Deployable Space Structures," LSS Workshop, Hampton VA August 24-25, 2004.

26 Francis, Will, Lake, Mark S., Mallick, Kaushik, Freebury, Gregg E., Engineering, G. Edward, and Maji, Arup, "Development and Testing of a Hinge/Actuator Incorporating Elastic Memory Composites," 44th AIAA/ASME/ASCE/AHS/ASC Structures, Structural Dynamics, and Materials Conference, April 7-10, 2003, Norfolk, VA.

27 Domber, Jeanette L., Hinkle, Jason, D., Peterson, Lee D. and Warren, Peter A., "Dimensional Repeatability of an Elastically Folded Composite Hinge for Deployed Spacecraft Optics," Journal of Spacecraft and Rockets, Vol. 39 No. 5 , p. 646.

28 Freeland, R. E., Bilyer, G. D., Veal, G. R. and Mikulas, M. M., "Inflatable Deployable Space Structures Technology Summary," IAF Paper 98-1.5.01, 1998.

29 Grahne, Ms S., Candogan, D. Sandy, C. R., and Moriyama, K. "Inflatable Space Structures: A New Paradigm for Space Structure Design," Presented at the $21^{\text {st }}$ International Symposium on Space Technology and Science, Omiya, Japan, May 24-31, 1998.

30 Allred, R. Harrah, L. Hoyt, A., McElroy, R., Wise, R., and Lou, M., "Inflatable Spacecraft using Rigidizationon-Command Concept," AIAA Paper 2000-1637, 2000.

31 Lichodziejewski, David, Veal, Gordon, Helms, Richard, Freeland, Robert, and Kruer, Mark; "Inflatable Rigidizable Solar Array for Small Satellites," AIAA 2003-1898, 44th AIAA/ASME/ASCE/AHS/ASC Structures, Structural Dynamics, and Materials Conference, April 7-10, 2003, Norfolk, VA.

32 Mitchell, Royce E. "Technology and the Hubble Space Telescope."AIAA Space Systems Technology Conference, AIAA No. 86-1229, 1986.

33 Seery Bernard D., "The James Webb Space Telescope (JWST): Hubble's Scientific and Technological Successor," Proceedings of SPIE, Vol. 4850, pp. 170-178, IR Space Telescopes and Instruments; John C. Mather; Ed. March 2003.

34 Thronson, Harley, "The Vision for Space Exploration and Large Space Systems in Science's Future," LSS Workshop, Hampton VA August 24-25, 2004.

35 R.A. Laskin, "The Space Interferometry Mission (SIM) - Meeting the Technology Challenge," Paper No. 387213, Photonics for Space and Enhanced Radiation Environments Conference (PSERE), European Optical Society/SPIE Symposium on Remote Sensing, Florence Italy, Sept '99. 
36 Dragovan, Mark, "The DART System for FarIR/Submillimeter Space Telescopes," Highly Innovative Space Telescope Concepts, Edited by Howard A. MacEwen. Proceedings of the SPIE, Vol. 4849, pp. 1-7 2002.

37 Chris Jenkins, "Membrane Mirrors", LSS Workshop, Hampton VA August 24-25, 2004.

38 NASA Broad Agency Announcement, "Research and Development Opportunities in Human and Robotic Technology,” BAA 04-02, July 28, 2004. 